\title{
Aa. Vv., Baudelaire, du dandysme à la caricature
}

\section{Philippe Andrès}

\section{(2) OpenEdition}

\section{Journals}

\section{Édition électronique}

URL : http://journals.openedition.org/studifrancesi/34997

DOI : 10.4000/studifrancesi.34997

ISSN : 2427-5856

Éditeur

Rosenberg \& Sellier

\section{Édition imprimée}

Date de publication : 1 novembre 2005

Pagination : 437-438

ISSN : 0039-2944

\section{Référence électronique}

Philippe Andrès, « Aa. Vv., Baudelaire, du dandysme à la caricature », Studi Francesi [En ligne], 146 (XLIX II) | 2005, mis en ligne le 30 novembre 2015, consulté le 19 avril 2021. URL : http://

journals.openedition.org/studifrancesi/34997 ; DOI : https://doi.org/10.4000/studifrancesi.34997

Ce document a été généré automatiquement le 19 avril 2021.

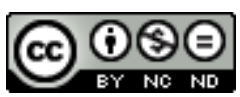

Studi Francesi è distribuita con Licenza Creative Commons Attribuzione - Non commerciale - Non opere derivate 4.0 Internazionale. 


\title{
Aa. Vv., Baudelaire, du dandysme à la caricature
}

\author{
Philippe Andrès
}

\section{RÉFÉRENCE}

AA. VV., Baudelaire, du dandysme à la caricature», «L'année Baudelaire», n 7, Paris, Honoré Champion, 2003, pp. 120.

Ce numéro s'inscrit sous la bannière de l'agrégation puisque Les Fleurs du Mal furent au programme du concours en 2003. On peut regretter que le titre n'indique pas une direction de lecture générale et que le projet de regrouper un certain nombre d'articles sur le rapport entre l'œuvre de Baudelaire et les sciences n'ait pas vraiment abouti faute de combattants. Le premier article de Françoise COBLECE, «Baudelaire, sociologue de la modernité» (pp.11-36) rappelle brièvement la méthode sociologique comme approche scientifique des œuvres littéraires et pose la question de la relation entre l'art et la science. S'ensuit une brève présentation de l'artiste en dandy bourgeois, au-delà $\mathrm{du}$ topos de la bohème et de l'ironie baudelairienne. La révolte du poète est évoquée ainsi que son flirt avec les socialistes utopiques et sa conception anti-rousseauiste de la société. De même, la foule semble beaucoup plus nuancée chez Baudelaire que chez les théoriciens de sciences sociales, comme Gabriel Tarde ou Gustave Le Bon, à la fin du $\mathrm{XIX}^{\mathrm{e}}$ siècle. À travers les topiques de la ville, de la femme et de la mode, Florence COBLECE effleure le concept de «modernité» définie - ce n'est pas nouveau - comme tension. Dans «Un dangereux pionnier, Baudelaire et l'histoire de l'art» (pp. 37-52), Pascal GRIENER s'intéresse à la réception des essais de critique rédigés par Baudelaire et du manque d'intérêt qu'ils auraient suscité. Comme la critique esthétique de Diderot, celle de Baudelaire s'inscrit dans un retard et un malentendu ainsi que le suggèrent les titres attribués de façon posthume: Curiosités esthétiques et L'Art romantique. La fine analyse proposée par Pascal GRIENER du Salon de 1846 souligne la complexité de la genèse de la critique esthétique baudelairienne assumant parfaitement le rôle économique de 
l'art. Pour Baudelaire, le Salon de 1846 est «le lieu du désarroi» (p. 43) et remet en question la notion même de progrès. Pascal GRIENER a réussi à nous convaincre de la distorsion de notre réception des Salons de Baudelaire, perçus comme «la légitimation d'une généalogie héroïque de l'art moderne» (p. 44). Il faut voir en Baudelaire critique d'art le «débusqueur de mythes historiques» (p.45); l'instigateur d'une nouvelle perception des petits maitres français du XVIII ${ }^{e}$ siècle, en dehors de toute nostalgie et l'incitateur d'une autre manière de considérer la surface matérielle du tableau exposé. Baudelaire critique d'art n'incarnerait-il pas la nouvelle figure d'un «Winckelmann moderne»? André GRIENER, dans «La religion (travestie) de Baudelaire» (pp.53-80), souligne les contradictions du poète et sa «dimension nietzschéenne incontestable» (p.67) et s'intéresse aux «fantasmes baudelairiens» (p. 72) concernant sa relation avec Jeanne. Cet article, fondé sur une démarche psychanalytique, montre, à partir d'une lecture de la correspondance, la complexité du vécu baudelairien et un Oedipe particulièrement prononcé, Jeanne Duval incarnant l'image négative d'une mère sublimée. Dans «La Théologie usée de Baudelaire» (pp. 81-90), Jean-Paul AvicE s'intéresse à l'expérience du désenchantement du monde pour Baudelaire tant sur le plan poétique que théologique. Dans l'humanité de Jésus acceptant son propre anéantissement se reflète, chez le poète, le besoin d'une théologie d'en bas conduisant à une transformation alchimique de la boue en or. Francesco SPADRI, quant à lui, dans «Les Fleurs du Mal et la pensée de l'ironie» (pp.91-100), fait remonter l'ironie baudelairienne au romantisme allemand et notamment à Friedrich Schlegel qui la considère sous l'angle métaphysique. Baudelaire lie l'ironie au lyrisme dans une «herméneutique de l'oblique» (p. 94). Il revient ensuite à John E. JACKSON de survoler «La question de Lesbos» (pp. 101-108), car Baudelaire «aurait compris dès l'enfance [...] la nature ou l'essence double de l'amour» (p. 101). Jacques Dupont et Claude Pichois livrent une courte réflexion sur «Paul Lafargue, lecteur de Baudelaire» (p. 109-110), qui aurait saisi, avant «le fort vanté Walter Benjamin», la position difficile du poète lyrique dans une société capitaliste en plein essor. Jacques DUPONT, dans «1851: sur une lecture conjecturale de Baudelaire» (pp. 111-112) nous livre une brève réflexion sur l'influence de Joseph de Maistre et de Sainte-Beuve sur Baudelaire. Finalement, dans le dernier article, «La caricature dans la poétique de Baudelaire» (pp. 113-120), Louis LEVY se propose de cerner les relations ambiguës entre l'art populaire et l'art officiel. La caricature ne serait-elle pas «la forme suprême de la création artistique» (p. 115) ?

2 Nous attendons avec impatience le prochain numéro de cette revue de qualité qui, souhaitons-le, trouvera plus d'homogénéité dans sa thématique et d'équilibre dans la longueur de ses articles. 